\title{
Histological Response of Clarias gariepinus to Varying Concentrations of Pharmaceutical Effluents
}

\author{
Ayandiran T. Akinpelu ${ }^{1}$, Ogundiran M. Akinloye ${ }^{1^{*}}$, Adewoye S. Olayinka ${ }^{1}$, \\ Opasola A. Olaniyi ${ }^{2}$, Olanipekun A. Stephen ${ }^{1}$ and Okaseun T. Oluwaseun ${ }^{3}$ \\ ${ }^{1}$ Environmental Biology Unit, Department of Pure and Applied Biology, Ladoke Akintola University of \\ Technology, Ogbomoso, Oyo State, Nigeria. \\ ${ }^{2}$ Department of Environmental Management and Toxicology, Kwara State University, \\ Malete, Nigeria. \\ ${ }^{3}$ Laboratory Research and Development Centre, National Biotechnology Development Agency, \\ Oka-Akoko, Ondo State, Nigeria.
}

\section{Authors' contributions}

This work was carried out in collaboration among all authors. Authors ATA and OMA designed the study, performed the statistical analysis, wrote the protocol including the first draft of the manuscript.

Authors OAO and OAS managed the analyses of the study. Author OTO managed the literature searches while Author ASO proof read the final draft of the manuscript. All authors read and approved the final manuscript.

\section{Article Information}

DOI: $10.9734 / A R R B / 2020 / v 35 i 430213$

Editor(s):

(1) Dr. Jean-Marie Exbrayat, Professor, Universite Catholique de Lyon, France. (2) Dr. George Perry, Dean and Professor of Biology, University of Texas at San Antonio, USA Reviewers:

(1) Dahiru Ibrahim, National Research Institute for Chemical Technology, Nigeria (2) Tiogué Tekounegning Claudine, University of Dschang, Cameroon. (3) Byron Baron, University of Malta, Malta. Complete Peer review History: http://www.sdiarticle4.com/review-history/49531

Original Research Article

Received 08 November 2018

Accepted 13 January 2019 Published 04 June 2020

\section{ABSTRACT}

For the past few decades, environmental pollution is considered a major global problem for public health and this problem has continued to impact aquatic environment. Pharmaceutical discharges are major sources of pollution that poses serious threat to aquatic animals like fish, therefore, this work aimed at evaluating the histological architecture of the gill tissues of Clarias gariepinus on exposed to sub-lethal concentrations of pharmaceutical effluents using standard laboratory procedure. The physicochemical characteristics of the pharmaceutical effluent used revealed varied level of deviations from World Health Organization standard for waste discharge into any 
categories of water bodies. The histological studies of the sectioned gills of the exposed fish showed varied level of histological alterations which are concentrations dependent. The observed histopathological lesions recorded include infiltration of secondary lamellae, inter-lamellae hyper plastic lesion, and oedema, congestion of the blood vessels, epithelial thickening and lifting, and necrosis of various degrees. All the fish held in the control stock showed inappreciable or no histological degradation and their staining patterns and cellular arrangement remained unaffected and this showed that even low concentration of such effluent is enough to induce physiological imbalances in aquatic organisms. The degrees of all these recorded anomalies were concentration dependent. Therefore, indiscriminate disposal of this effluent is detrimental to aquatic community and to combat this, strict compliance of the laws with total vigilance against illegal discharge of effluent should be enacted and enforced.

Keywords: Histology; pharmaceutical effluent; African cat fish.

\section{INTRODUCTION}

Water quality can be described as the physical, chemical, biological and aesthetic properties of water, which determine its fitness for use and consumption, and its ability to maintain the integrity and health of an ecosystem [1]. Increasing contamination of the aquatic environment worldwide has been associated with improper discharge of solid wastes, industrial, medical and agricultural effluents [2-4]. Pharmaceutical effluents contain mixture of various classes of organic and inorganic micropollutants that are capable of inducing toxicological effects on aquatic organisms. There are several reports on the presence of pharmaceuticals and their metabolites in most aquatic environments worldwide [5-7].

Many of these reports showed that these pharmaceuticals were commonly observed in aquatic environments of most high income nations, with very scanty information from lowand middle-income countries [7]. In Nigeria, due to high cost of effluent treatment technology, most industries illegally discharge untreated effluent directly into aquatic environment. This act is worrisome and has elicited public concern due to increasing occurrence of drugs and metals in coastal waters via Nigerian waterways [8]. Also, [9] reported eight acidic pharmaceuticals; four antipyretics (Ibuprofen, Ketoprofen, Diclofenac and Aspirin), three antibiotics (Ampicillin, Ciprofloxacin and Nalidixic acid), and one lipid regulator (Bezafibrate) in wastewater, surface water, and sediments from Msunduzi River in the province of KwaZuluNatal, South Africa while [8] observed thirty seven pharmaceuticals classified as antibiotics, estrogens and lipid-lowering drugs in surface water and industrial, domestic and hospital sewage sludge from Lagos State, Southwest, Nigeria.

These Pollutants build up in the food chain and are responsible for the adverse effects and death in aquatic organisms [10]. Fish are widely used to evaluate the health of aquatic ecosystem and their physiological changes serve as biomarkers of environmental pollution [11]. Clarias gariepinus is most widely used because it is hardy since it is able to tolerate both well and poorly oxygenated waters. It is widely cultivated in Nigerian water bodies, hence used as biological indicators of ecotoxicological studies. Thus, the aim of this study is to investigate the toxicity of varying concentrations of pharmaceutical effluent on C. gariepinus gills as biomarkers of environmental quality in aquatic environment.

\section{MATERIALS AND METHODS}

\subsection{The Sample Site and Collection}

The pharmaceutical effluent used in this toxicity test was collected from the discharge point of an indigenous Pharmaceutical Industry, along Yidi road $\left(8^{\circ} 28^{\prime} 33.65^{\prime \prime} \mathrm{N}\right.$ $4^{\circ} 33^{\prime} 8.16 "$ E), llorin, Kwara State, Nigeria. The company produces analgesics, anti-malarias, multivitamins, antibiotics, and human vaccines. The effluent samples were collected using pre cleaned plastic kegs and the $\mathrm{pH}$ of the samples were taken at the point of collection.

C. gariepinus of sizes between $100 \mathrm{~g}$ and 300 $\mathrm{g}$ were procured from the Fisheries Department, Oyo State Ministry of Agriculture and Natural Resources, Ogbomoso, Oyo State, Nigeria. Aerators pumps were employed for proper oxygen dissolution during the exposure period. 
The test organisms were acclimatized for three weeks during which the water was renewed daily (renewable bioassay procedure) and the fish were fed with conventional fish-feed pellet once daily.

\subsection{Physicochemical Analysis}

The physical and chemical parameters; total solids, total dissolved solids, biochemical oxygen demand (BOD), chemical oxygen demand (COD), dissolved oxygen (DO), alkalinity, oil and grease, total hardness and conductivity were analyzed using standard methods (12).

\subsection{Histological Preparation}

After the $96 \mathrm{hrs}$ exposure, LC $_{50}$ was determined and five different concentrations were set up on the basis of the $\mathrm{LC}_{50}$ value obtained and these were $0.04,0.06,0.08,0.10$ and $0.12 \mathrm{mgL}^{-1}$. A control experiment was also set up. The solutions were renewed (renewable bioassay) every 48 hours and the entire exposure period was 45 days. After 45 days, the gills were removed and prepared for probable histological degradations. The organisms were decapitated, dissected and assessed individually by separating the experimental fish from the control fish. After proper dissection, the gills were carefully removed and small pieces were fixed in Bouin's Fluid, after which, the gills were dehydrated through a series of graded alcohol, cleared in xylene, infiltrated with paraffin in a vacuum oven dried at $56^{\circ} \mathrm{C}$, then embedded in paraffin wax. Sections of 6 microns thickness were cut, mounted and stained with heamatoxylin and eosin. Each section was then used to make slides of tissue and was observed under the microscope for proper description of their histological structures, appearance, and cell arrangement. The respective photomicrographs of the slides were also taken for proper observations and interpretations [12].

\section{RESULTS}

\subsection{Physicochemical Analysis}

Table 1 reveals the physic-chemical properties of the pharmaceutical effluent used and virtually all the parameters analyzed were found to deviate from the World Health Organization [13] permissible limit for discharge into all categories of water bodies.

\subsection{Histological Analysis}

The gills of fish specimens in the control experiment showed normal central vessel without any sign of congestion. The lamellae consist of normal erythrocyte, chloride and pillar cells with the gill arch showing normal osteocyte-like cells. The gill rakers are well arranged with no visible evidence of lesion (Fig. 1). The gill structure of all exposed fish showed varied level of gill damage which is concentration dependent and this range from hypertrophyto desquamation of lamellae epithelium, oedema, swelling of pillar and chloride cell and cellular necrosis (Figs. $2-6$ ).

\section{DISCUSSION}

The obtained values for Total suspended solids, Total solids, $\mathrm{pH}$, dissolved oxygen, Biological oxygen demand, Total hardness, Alkalinity, and conductivity deviated from WHO [12] standard for waste discharge into water bodies. This might have resulted from the organic loads in the effluent, which serves as a suitable medium for microorganisms that competes with the test organisms for the utility of the limited available

Table 1. Physico-chemical characteristics of the pharmaceutical effluent used

\begin{tabular}{llc}
\hline Parameter & Effluents value & who standard (2011) \\
\hline pH & 6.2 & $6.5-9.5$ \\
Dissolved Oxygen $(\mathrm{Mg} / \mathrm{L})$ & 0.7 & 6.0 \\
Total Solids $(\mathrm{Mg} / \mathrm{L})$ & 845 & $<1000$ \\
Total Dissolved Solid $(\mathrm{Mg} / \mathrm{L})$ & 1066 & $<1000$ \\
Biochemical Oxygen Demand $(\mathrm{Mg} / \mathrm{L})$ & 15.02 & 30 \\
Chemical Oxygen Demand $(\mathrm{Mg} / \mathrm{L})$ & 89 & 100 \\
Oil and Grease $(\mathrm{Mg} / \mathrm{L})$ & 18 & 30 \\
Alkalinity $(\mathrm{Mg} / \mathrm{L})$ & 4.41 & $\overline{<200}$ \\
Total Hardness $(\mathrm{Mg} / \mathrm{L})$ & 71.11 & \\
Conductivity $(\mu \mathrm{S})$ & 7.78 & \\
\hline
\end{tabular}




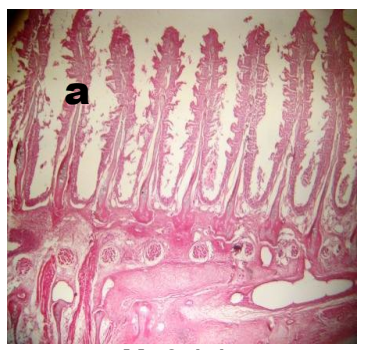

$\mathrm{X} 40$ (a)

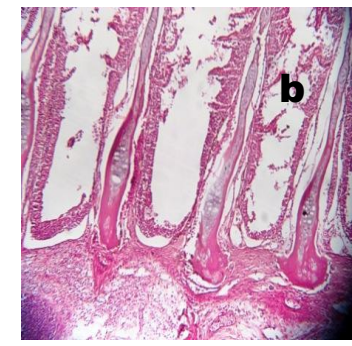

$\mathrm{X} 100$ (b)

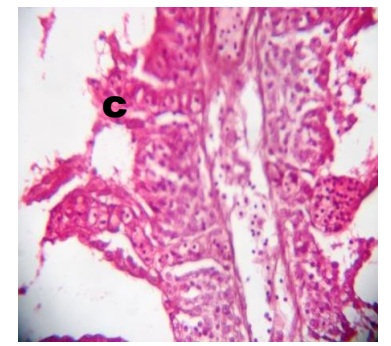

$\mathrm{X} 400(\mathrm{c})$

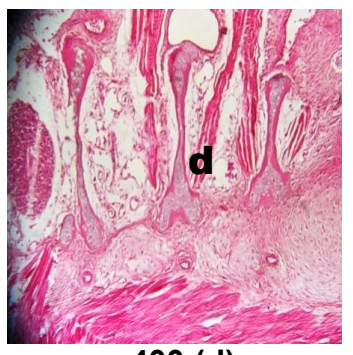

X400 (d)

Fig. 1. Photomicrograph of fish gill section in the control stock stained by haematoxylin and eosin showing normal gill lamellae (a) and arch (d). The lamellae consisting of normal erythrocytes, chloride cells and pillar cells(c). The gill arch shows normal osteocyte-like cells

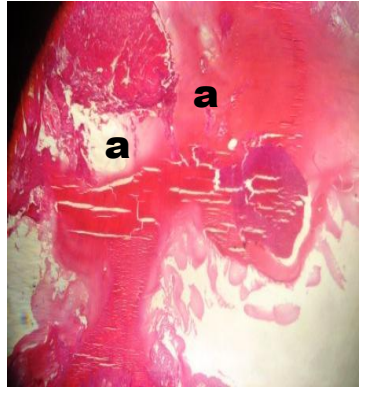

$\mathbf{x} 40$ (a)

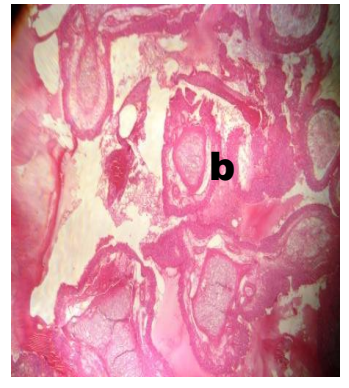

x100(b)

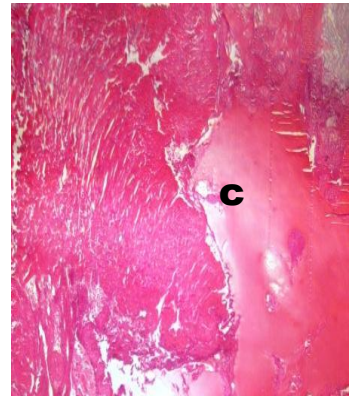

$\mathbf{x 1 0 0}$ (c)

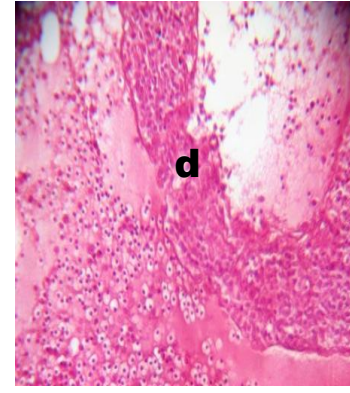

x400 (d)

Fig. 2. Photomicrograph of fish gill sectionat $0.04 \mathrm{mg} / \mathrm{l}$ stained by haematoxylin and eosin showing distrupt gill lamellae (cross sectional) (b) and there is severe haemorrhage (a) and moderate oedema/ fluid accumulation (c) within the gill arch. areas of fluid and infiltrating inflammatory celle are seen (d)

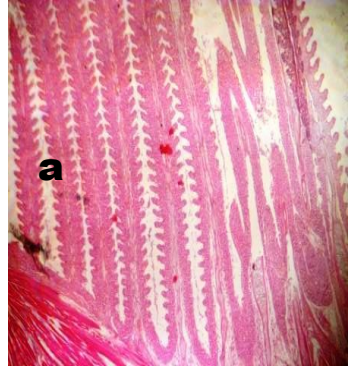

$\mathbf{x 4 0}$ (a)

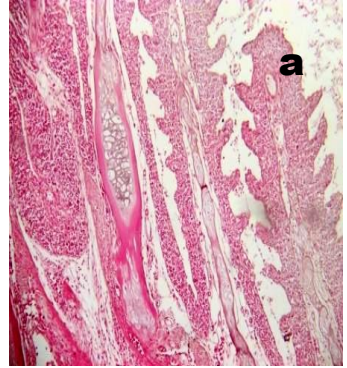

$\mathrm{x100}(\mathrm{b})$

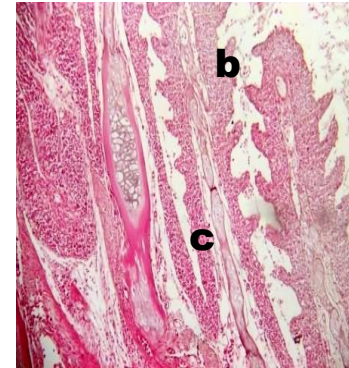

$x 100$ (c)

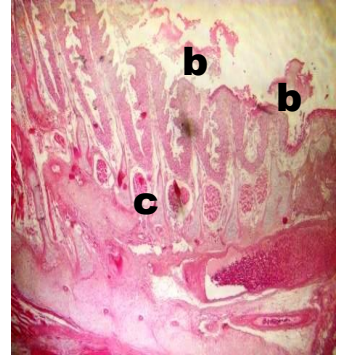

$\mathrm{x400}$ (d)

Fig. 3. Photomicrograph of fish gill section at $0.06 \mathrm{mg} / \mathrm{l}$ stained by haematoxylin and eosin showing normal gill lamellae and arch. the lamellae (a) consisting of areas of normal erythrocytes, chloride cells and pillar cells as well as pale and necrotized cellular elements (b) and thus appear fused and distrupted, the gill arch shows necrotized osteocytes and cartilage cells (c)

dissolved oxygen. Though the values obtained may be lower than the standard permissible limit of $\mathrm{WHO}$ [12] but that is not to undermine their additive or residual effects on the organisms' activities including their physiological state which may impair organs like the gills, liver, kidney and other vital organs.
C. gariepinus is a suitable bio-indicator for monitoring the toxicity of effluents [4]. Changes in the histology of tissues in fish have been widely used, both in laboratory regulated experiments [14] and field studies [15] to assess fish health. Previous histopathological studies of fish exposed to pollutants have shown that fish gills 
are efficient indicators of water quality and their vulnerability to pollutants in water is due to their large surface area and location [16]. However, the gills perform numerous functions such as respiration, excretion of nitrogenous waste products and acid-base balance.

Functional impairments of gills caused by pollutants may cause significant damages to the health of the fish. In this study, zero impairment was observed in the gills of the control fish each gill consists of primary filament and secondary lamellae which conformed with the submission of [17]. The experimental fish exposed to the pharmaceutical effluent concentrations showed some signs of stress and imbalance, erratic movement, gasping for breath, over secretion of mucus and loss of equilibrium [16]. The stressful and erratic behavior of the fish in this investigation gives a signal to respiratory impairment, and this may be as a result of the effect of the pharmaceutical effluent on the gills [18].

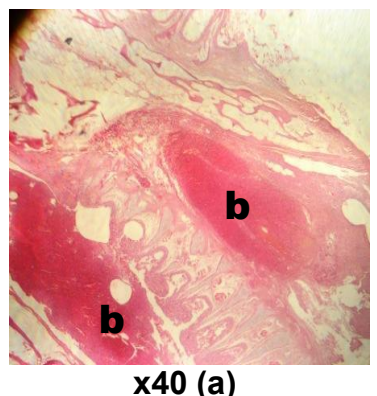

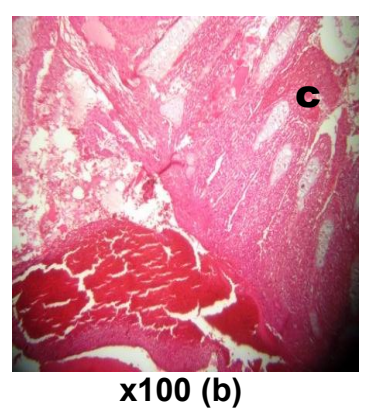

All histopathological lesions observed in the gills of $C$. gariepinusin this study were categorized under cellular infiltration (Fig. 2d), desquamation (displacement of epithelial cells), oedematous manifestation (Fig. 2C) and cellular necrosis (Fig. $3 \mathrm{~b}$ and $\mathrm{c}$ ), severe vascular congestion (Figs. 4a and $6 \mathrm{~b}$ ) moderate atrophy (Fig. 5c); these findings were virtually linked with the exposure of the test organisms to the simulated polluted environment, diffusion distance from surrounding water to capillaries and at the same time an increase in the amount of tissue (blood corpuscles) in the blood spaces of secondary lamellae and this correspond with the opinion of $[19,20]$; where such anomalies was reported in the gill structure of Oreochromis niloticus exposed to glyphosate herbicidal, waterborne copper and lead respectively.Similar result was also observed by [4] where severe congestion of the blood capillaries, necrosis and thickening of the gill filament and disorganization of the lamellae in pharmaceutical effluent exposed $C$. gariepinus and this showed that constituents of
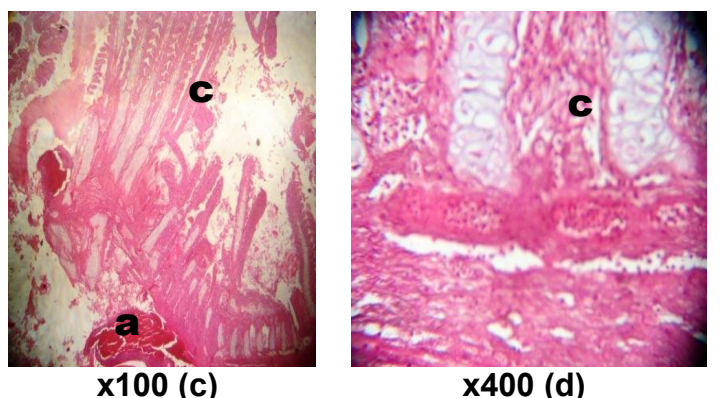

Fig. 4. Photomicrograph of fish gill section at $0.08 \mathrm{mg} / \mathrm{l}$ stained by haematoxylin and eosin showing severe vascular congestion (a) and haemorrhage (b).the gill arch is infiltrated by diffused red cells and the filaments show erythrocytes and epithelial cells hyperplasia and moderate degeneration (c)

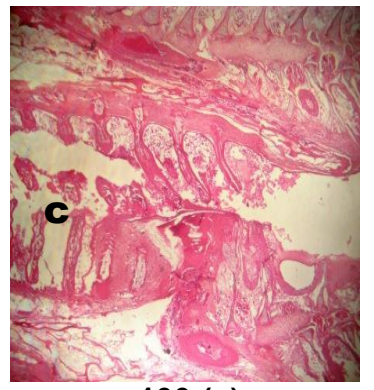

$\mathbf{x 1 0 0 ( a )}$

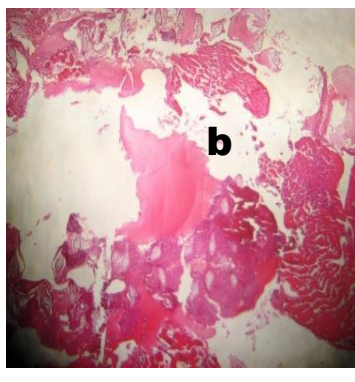

x100 (b)

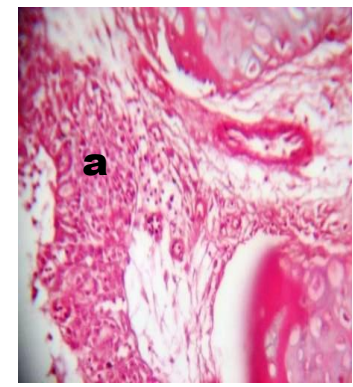

X400 (c)

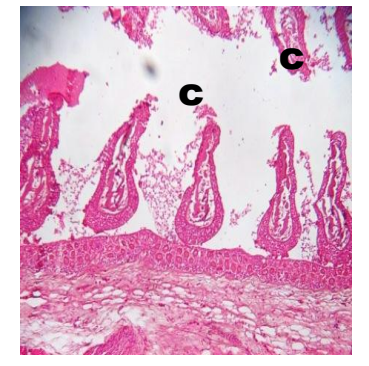

$x 400$ (d)

Fig. 5. Photomicrograph of fish gill section at $0.1 \mathrm{mg} / \mathrm{l}$ stained by haematoxylin and eosin showing severe infiltration of inflammatory cells (a) within the gill arch. There is mild accumulation of fluid (b). the filaments show moderate atrophy(c) 


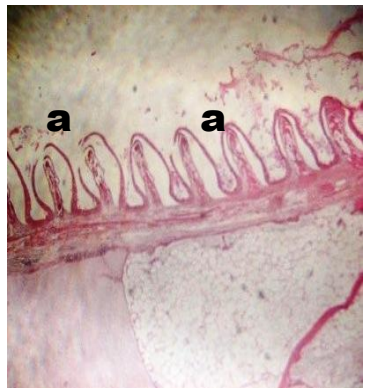

x40 (a)

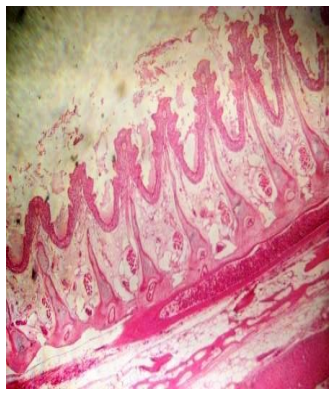

$\mathbf{x} 100$ (b)

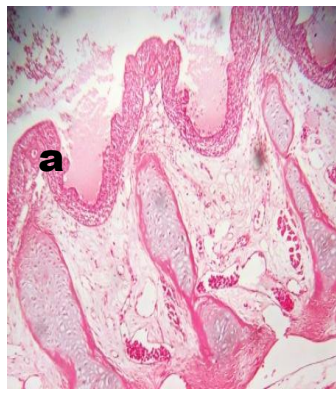

$x 100$ (c)

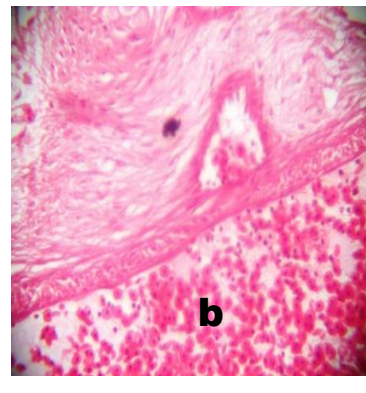

$x 400$ (d)

Fig. 6. Photomicrograph of fish gill section at $0.12 \mathrm{mg} / \mathrm{l} \mathrm{stained} \mathrm{by} \mathrm{haematoxylin} \mathrm{and} \mathrm{eosin}$ showing severely atrophied laminae (a), the gill arch is severely infiltrated by diffused red cells (b) and severe congestion within the vessel

the effluent caused structural alterations on the gills.

The effluent constituents came in direct contact with the gills and considering that the gill filaments and lamellae have increase surface area of exposure to contaminants, makes gills the most critical site of toxicity $[21,22]$. Also considering that the gills are highly metabolically active, they are readily prone to damage from environmental micro-pollutants, mostly the toxic metals via oxidative stress induction [23]. The cellular hypertrophic condition observed in this study led to a decrease in the respiratory capacity between the lamellae, impaired the diffusion of oxygen across the gills due to the swollen condition of the epithelium. It could also be likened to a decrease in free gas exchange which in turn limits the compensatory changes that makes organism to become intolerable when the duration of exposure and the concentrations of the effluents exceeded biological tolerance limits and this result is in line with the submission of $[24,25]$. Damages done to the gills indicated that the sub lethal level of this metals mixture caused impairment in gaseous exchange efficiency of the gills [20].

Moreover, the presence of mucous-filled cavity (oedema) observed in the gill filaments of Clarias gariepinus may be considered as an ion trap, in a way to concentrate free elements from surrounding water between the neighbouring secondary lamellae; Also, the presences of white blood cells in the form of macrophages, lymphocyte and neutrophils aggregation in the oedematous cell clearly indicated an inflammatory reaction and cellular response of the fish to environmental contaminants [26].

The presence of mucous over the body surface of the test fish was noticed to gradually increase and this is a reflection of the hyperplastic glandular cells activity in the dermis of exposed fish. The concomitant appearance of inflammatory cells was also an indication of a secondary defence mechanism of the body against infections and this conforms to the research of [20]. It may as well serve to protect the epithelial against both mechanical abrasion and infection as submitted by $[20,27,28]$. The changes recorded in the gill structure of the test fish in this study were indicative of diminished oxygen supply to the test fish, resulting in hypoxic respiratory response, though not lethal but not reversible.

\section{CONCLUSIONS}

Conclusively, this study has demonstrated that the prevailing practice of unregulated and uncontrolled discharge of effluent into water bodies poses a serious threat to aquatic organisms. This study had also shown that pharmaceutical effluent contains varying concentrations of toxic metals, metalloids and physicochemical parameters higher than standard permissible limits. The effluent induced histopathological lesions in gills, of Clarias gariepinus and this suggests the constituents of pharmaceutical effluents is an emerging pollutants that are capable of causing pathological lesions in aquatic organisms' tissues, thereby posing a threat to the functioning aquatic ecosystems, survival and diversity of aquatic biota.

\section{COMPETING INTERESTS}

Authors have declared that no competing interests exist.

\section{REFERENCES}

1. Department of Water Affairs Water quality concepts; 2010.

Available:http://www.dwaf.gov.za 
2. Ibekwe AM, Leddy MB, Bold RM, Graves AK. Bacterial community composition in low-flowing River water with different sources of pollutants. FEMS Microbiol. Ecol. 2012;79:155-66.

[PubMed] [Google Scholar]

3. Larsson DGJ. Pollution from drug manufacturing: review and perspectives. Philos Transact Royal SocB. 2014;369:17.

[PMC free article] [PubMed] [Google Scholar]

4. Alimba C, Adekoya KO. Soyinka OO. Exposure to effluent from pharmaceutical industry induced cytogenotoxicity, hematological and histopathological alterations in Clarias gariepinus (Burchell, 1822). Excli J. 2019;18:63-78.

5. Zuccato E, Calamari D, Natangelo M., Fanelli R. Presence of therapeutic drugs in the environment. Lancet. 2000;355:178990.

[PubMed] [Google Scholar]

6. Nikolaou A, Meric S, Fatta D. Occurrence patterns of pharmaceuticals in water and wastewater environments. Anal Bioanal Chem. 2007;387:1225-34.

[PubMed] [Google Scholar

7. Kookana RS, Williams M, Boxall ABA, Larsson DGJ, Gaw S, Choi K. Potential ecological footprints of active pharmaceutical ingredients: An examination of risk factors in low-, middleand high-income countries. Philos. Transact. Royal. Soc. B. 2014;369:1-16.

[PMC free article] [PubMed] [Google Scholar]

8. Olarinmoye O, Bakare A, Ugwumba O, Hein A. Quantification of pharmaceutical residues in wastewater impacted surface waters and sewage sludge from Lagos, Nigeria. J Environ Chem. Ecotoxicol. 2016; 8(3):14-24.

[Google Scholar]

9. Agunbiade F. Moodley B. Occurrence and distribution pattern of acidic pharmaceuticals in surface water, wastewater, and sediment of the Msunduzi River, KwaZulu Natal, South Africa. Enviro nmental Toxicology Chem. 2016;35:3646.

[PubMed] [Google Scholar]

10. Kock G, Triendi M, and Hofer R. Seasonal pattern of metal accumulation in Arctic char (Salvelinus alpinus) from an oligitriphic Alpine lake related to temperature. Can. J. Fish. Aquat. Sci. 1996;53:780-786.

11. Odiete WO. Impacts associated with water pollution. In: Environmental physiology of Animals and pollution. 1st edition. Diversified Resources Ltd, Lagos, Nigeria. 1999;187-219.

12. World Health Organization (WHO). International Standards for Drinking Water, $6^{\text {th }}$ Edition. World Health Organization; 2011.

13. APHA. Fixation, Tissue Processing, Histology And Immunohistochemistry Procedures For Diagnosis of Animal Tse (Bse, Scrapie, Atypical Scrapie, Cwd). Pathology Department, APHA. 2018;11.

14. Mela M, Randi MAF, Ventura DF, Carvalho CEV, Pelletier E, Oliveira RCA. Effects of dietary methylmercury on liver and kidney histology in the neotropical fish, Hoplias malabaricus. Ecotoxicol. Environ. Safety. 2007;68:426-35.

[PubMed] [Google Scholar]

15. Alimba CG, Ajiboye RD, Fagbenro OS. Dietary ascorbic acid reduced micronucleu $s$ and nuclear abnormalities in Clarias gariepinus (Burchell 1822) exposed to hospital effluent. Fish Physiol Biochem. 2017;43:1325-1335.

[PubMed] [Google Scholar]

16. Agboola, Fawole. Covenant Journal of Physical and Life Sciences (CJPL). 2014; 1(2).

17. António FF, Jorge VF, Sofia G, Sandra M, João $C$, Pedro $M$, António $F$. Histopathological changes in liver and gill epithelium of Nile tilapia, Oreochromis niloticus, exposed to waterborne copper. Pesq. Vet. Bras. 2007;27:3 Rio de Janeiro.

18. Junqueira LC, Carneiro J. Basic Histology. 10th Edn, Lange Edition, McGraw limitation; 2003.

19. Olojo EAA, Olurin KB, Mbaka G, Oluwemimo AD. Histopathology of gills and liver tissues of the African catfish Clariasgariepinus exposed to lead. Afr. J. Biotech. 2005;4(1):117-122.

20. Ayoola SO. Histopathological Effects of Glyphosate on juvenile African Catfish (Clarias gariepinus) Ameri-surasian $\mathrm{J}$ Agric\& Environ Sci. 2008a;4(3):362-367.

21. Evans $\mathrm{DH}$. The fish gill: Site of action and model for toxic effects of environmental pollutants. Environ Health Perspect. 1987; 71:47-5. 
[PMC free article] [PubMed] [Google Scholar]

22. Wood CM, Kelly SP, Zhou B, Fletcher M, O'Donnell M, Eletti B. Cultured gill epithelia as models for the freshwater fish gill. Biochem. Biophy. Acta. 2002;1566:7283.

\section{[PubMed] [Google Scholar]}

23. Farombi EO, Adelowo OA, and Ajimoko YR. Biomarkers of oxidative stress and heavy metal levels as indicators of environmental pollution in African cat fish (Clarias gariepinus) from Nigeria Ogun River. Int $J$ Environ Res Public Health. 2007;4:158-65.

[PMC free article] [PubMed] [Google Scholar]

24. Gardner G, Yevich, T. Impact of certain heavy metals on the gill and liver of the nile tilapia (Oreochromis niloticus). Journal of the Fisheries Research Board of Canada. 1970;27:70-248.
25. Wedemeyer GA, Barton BA, McLeay DJ. Stress and acclimation. In C. B. Schreck and P. B. Moyle (eds.), Methods for fish biology. American Fisheries Society, Bethesda, Maryland. 1990;451-489.

26. Zeeman M, Brindley WA. Effects of toxic agemt upon fish immune system: a review. In: Immunologic considerations in Toxicology. Vol 2, Dharma RP, ed.CRC Press, Inc, Boca Raton, FL. 1981;1-60.

27. Olson K, Fromm PO. A scanning electron microscopic study of secondary lamellae and chloride cells of rainbow trout (Salmo gairdneri). Zeitschriftfür Zellforschung und Mikroskopische Anatomie. 1973;/143(4): 439-449

28. Ogundiran MA, Fawole OO, Adewoye SO, Ayandiran TA. Pathologic lesions in the gills structures of Clarias gariepinus on exposure to sub-lethal concentrations of soap and detergent effluents. Journal of Cell and Animal Biology. 2009;3(5): 078082.

(c) 2020 Akinpelu et al.; This is an Open Access article distributed under the terms of the Creative Commons Attribution License (http://creativecommons.org/licenses/by/4.0), which permits unrestricted use, distribution, and reproduction in any medium, provided the original work is properly cited.

Peer-review history:

The peer review history for this paper can be accessed here: http://www.sdiarticle4.com/review-history/49531 